\title{
ФИЗИКА В ЕNЕМ И В КУРСЕ ТЕХНИЧЕСКОЙ ХИМИИ В ФЕДЕРАЛЬНОМ ИНСТИТУТЕ АМАПЫ (IFAР): СРАВНЕНИЕ УЧЕБНЫХ ПРОГРАММ
}

\section{ОРИГИНАЛЬНАЯ СТАТЬЯ}

CARMO, Denny Rodrigues do', BASTOS, Argemiro Midonês², FECURY, Amanda Alves $^{3}$, DENDASCK, Carla Viana ${ }^{4}$, OLIVEIRA, Euzébio de ${ }^{5}$, DIAS, Claudio Alberto Gellis de Mattos $^{6}$

CARMO, Denny Rodrigues do. Et al.Физика в ENEM и в курсе технической химии в Федеральном институте Амапы (IFAP): сравнение учебных программ. Revista Científica Multidisciplinar Núcleo do Conhecimento.Год 06, изд. 03, том 03, стр. 80-88. Март 2021 г. ISSN: 2448-0959, Ссылка для доступа: https://www.nucleodoconhecimento.com.br/образование-ru/сризика-вenem, DOI: 10.32749/nucleodoconhecimento.com.br/ru/78516

\section{АБСТРАКТНЫЕ}

Национальный экзамен для старших классов средней школы (ENEM) - это оценочный и выборочный инструмент для студентов, поступающих в высшие

\footnotetext{
${ }^{1}$ Студент технического курса химии (средняя школа) Института базового, технического и технологического образования Amapá (IFAP).

2 Физик, доктор философии по биоразнообразию и биотехнологии (UFPA), профессор и исследователь курса физики в Базовом техническом и технологическом институте Amapá (IFAP) и программы последипломного профессионального и технологического образования (PROFEPT IFAP).

${ }^{3}$ Биомедицина, доктор актуальных болезней, профессор и исследователь курса медицины в кампусе Масара́, Федеральный университет Amapá (UNIFAP).

${ }^{4}$ Богослов, кандидат клинических психоанализов. Он проработал 15 лет с научной методологией (методом исследования) по ориентации научного производства студентов магистратуры и докторантуры. Специалист по маркетинговым исследованиям и исследованиям в области здравоохранения.

${ }^{5}$ Биолог, доктор актуальных болезней, профессор и исследователь курса физического воспитания в Федеральном университете Pará (UFPA).

${ }^{6}$ Биолог, доктор теории поведения и исследований, профессор и исследователь химического факультета Института базового, технического и технологического образования Amapá (IFAP) и последипломной программы профессионального и технологического образования (PROFEPT IFAP).
}

RC: 78516

Disponível em: https://www.nucleodoconhecimento.com.br/образование-ru/сризика- 
учебные заведения. Федеральные институты образования, науки и технологий (IFs) - это учреждения, созданные федеральным правительством с целью подготовки компетентных специалистов. Целью данного исследования является сравнение содержания вопросов по фризике Национального экзамена в средней школе (ENEM) в период с 2014 по 2018 год с содержанием учебной программы курса технической химии в Федеральном институте Амапа (IFAP). B преподавании фризики на техническом курсе химии в IFAP нет раздела, который отдавал бы приоритет наиболее актуальным предметам в ENEM. ENEM обычно контекстуализирует свои вопросы. Это может быть обычной практикой в фризике средней школы, так как это поможет вам лучше понять. Кроме того, необходимо не фрагментировать содержание во время обучения, а также не совмещать его с другими предметами. Технический курс в IFAP не будет подходящим местом обучения для тех, кто просто хочет закончить среднюю школу. Содержание выходит за рамки того, что требуется, но с вырезами, ориентированными на техническую часть, включая лабораторные практики и строго технические дисциплины. Отсутствие междисциплинарности и контекстуализации затрудняет усвоение содержания, фрормируя у учащихся трудности с мышлением о фризике.

Ключевое слово: ENEM, EPT, Обучение, Физика, IFAP

\section{ВСТУПЛЕНИЕ}

Национальный экзамен в средней школе (ENEM), учрежденный фредеральным правительством Бразилии в 1998 году, был направлен на оценку учащихся, окончивших среднюю школу. Со временем ENEM получил больше, когда использовался не только как инструмент оценки, но и как выборочный инструмент для поступления студентов в высшие учебные заведения (Silveira et al., 2015).

$\mathrm{RC}: 78516$

Disponível em: https://www.nucleodoconhecimento.com.br/образование-ru/фризика- 
В тесте ENEM к предмету фризики подходят наряду с предметами биологии и химии в области естествознания. Несмотря на отсутствие фоорального разделения, можно увидеть, что вопросы естествознания могут быть организованы по трем дисциплинам путем анализа охваченного содержания. (Silveira et al., 2015).

Федеральные институты образования, науки и технологий - это учреждения, созданные фредеральным правительством с целью подготовки компетентных специалистов. Они могут представлять разные курсы, такие как бакалавриат, магистратура или докторская степень, но основной фрормой является техническое образование, в основном техническое образование, интегрированное со средней школой (Pacheco, 2010).

В Бразилии во всех штатах есть по крайней мере один фредеральный институт, в некоторых - даже более одного, всего 38 отделений. Федеральный институт может быть разделен на кампусы, в которых в настоящее время работает 644 института. (Brasil, 2018).

Федеральный институт образования, науки и технологий штата Амапа (IFAP) был создан 28 декабря 2008 г. в соответствии с Законом № 11,892 (Marques et al., 2020) и направлен на содействие развитию штата (Castro et al., 2020). IFAP предлагает курсы от высшей до старшей школы, и при этом ему удается охватить широкую аудиторию на разных уровнях, он также состоит из нескольких кампусов, из которых мы можем упомянуть кампус Macapá, расположенный в столице (Brasil, 2019; Penha et al., 2020).

Кампус Масара́ предлагает комплексный технический курс химии для старших классов. В этом курсе у нас есть компоненты учебной программы Национальной общей базы, относящиеся к областям языков, математики, гуманитарных и естественных наук. В области естественных наук у нас есть учебный компонент по физике, который изучается в течение трех лет курса.

$\mathrm{RC}: 78516$

Disponível em: https://www.nucleodoconhecimento.com.br/образование-ru/фризика- 
Ежегодная рабочая нагрузка составляет 80 часов в год, а преподаваемое содержание разделено на четыре блока, всего 12 блоков за три года. (Brasil, 2016).

В Федеральном институте Амапы (IFAP) предметами меню компонента «Физика» первого года интегрированного технического курса являются: Введение в фризику и кинематику; Динамика; Работа и энергия (что также включает количество движения и импульс); Гравитация и статика жидкости. В программу второго года обучения входят: «Тепло и температура»; Термодинамика; Геометрическая оптика; Колебания и волны (включая простое гармоническое движение). В третий и последний год содержание: электростатическое; Электродинамика; Магнетизм; и электромагнетизм (Brasil, 2016).

В матрице учебного плана Enem есть компетенции и объекты знаний, связанные с этими компетенциями. Объекты знаний, относящиеся к физике, собраны по 7 темам: базовые и фундаментальные знания (включая предметы размерного анализа и систем единиц); движение, баланс и открытие фризических законов (включая кинематику, динамику, гидростатику, статику, импульс и количество движения); энергия, работа и мощность (включая вопросы, связанные с работой и энергией); механика и фуннционирование Вселенной (включая предметы, связанные с гравитацией); электрические и магнитные явления (с предметами, связанными с электричеством и магнетизмом); колебания, волны, оптика и излучение (включая предметы от оптики до волн); а также тепло и тепловые явления (включая вопросы, связанные с термологией) (Brasil, 2015).

\section{ЦЕЛИ}

Сравните содержание вопросов по фризике Национального экзамена для старших классов средней школы (ENEM) в период с 2014 по 2018 год с

$\mathrm{RC}: 78516$

Disponível em: https://www.nucleodoconhecimento.com.br/образование-ru/фризика- 
содержанием учебной программы курса технической химии в Федеральном институте Амапы (IFAP).

\section{МАТЕРИАЛ И МЕТОДЫ}

Исследование проводилось с использованием вопросов Национального экзамена для старших классов средней школы (ENEM), взятых из программы (software) Супер учитель (Super Professor), полученной от компании Interbits Вычисление (https://www.sprweb.com.br/mod_superpro/index.php ). В программе были выбраны фризическая дисциплина и период с 2014 по 2018 г. Вопросы были классифицированы в соответствии с программой (после анализа и удаления перекрывающихся вопросов). Впоследствии было проведено сравнение между ними и программой фризического компонента технического курса Федерального института Амапы (IFAP). Библиографрические исследования проводились по научным статьям на компьютерах Института Федерального института образования, науки и технологий Амапы, кампус Макапа, расположенного по адресу Rodovia BR 210 KM 3, s / n - Bairro Brasil Novo. CEP: 68.909-398, Macapá, Amapá, Brazil. Данные были собраны в приложении Excel, входящем в пакет Office корпорации Microsoft.

\section{ПОЛУЧЕННЫЕ РЕЗУЛЬТАТЫ}

Классификация перекрывающегося содержания вопросов по физике ENEM в период с 2014 по 2018 год по количеству и проценту вопросов представлена в таблице 1. Три (3) предмета не представляют никаких вопросов (размерный анализ / система единиц, гравитация и современная фризика). У большинства предметов есть один (1) или два (2) вопроса. Электричество + магнетизм и кинематика представляют по 4 вопроса. Шесть (6) вопросов относятся к предмету Работа и Энергия, а также к предмету Оптика. Тема «Волна» состоит из 17 вопросов.

$\mathrm{RC}: 78516$

Disponível em: https://www.nucleodoconhecimento.com.br/образование-ru/фризика- 
Таблица 1 Классификация перекрывающегося содержания вопросов по фризике ENEM в период с 2014 по 2018 год, по количеству и проценту вопросов.

\begin{tabular}{|c|c|c|}
\hline \multicolumn{3}{|c|}{ Classificação do autor após análise de conteúdo sobreposto } \\
\hline Conteúdo de Física & Quantidade & Porcentagem \\
\hline Análise Dimensional / Sistemas de Unidades & 0 & $0 \%$ \\
\hline Gravitação & 0 & $0 \%$ \\
\hline Moderna & 0 & $0 \%$ \\
\hline Cinemática + Impulso e Quantidade de Movimento & 1 & $2 \%$ \\
\hline Dinâmica + Impulso e Quantidade de Movimento & 1 & $2 \%$ \\
\hline Hidrodinâmica & 1 & $2 \%$ \\
\hline Hidrostática & 1 & $2 \%$ \\
\hline Trabalho e Energia + Movimento Harmônico & 1 & $2 \%$ \\
\hline Temática + Trabalho e energia & 1 & $2 \%$ \\
\hline Tematica & 1 & $2 \%$ \\
\hline Cinemática + Dinâmica & 2 & $3 \%$ \\
\hline Dinâmica & 2 & $3 \%$ \\
\hline Estática & 2 & $3 \%$ \\
\hline Impulso e Quantidade de Movimento & 2 & $3 \%$ \\
\hline Trabalho e Energia + termologia & 2 & $3 \%$ \\
\hline Eletricidade + Magnetismo & 4 & $7 \%$ \\
\hline Cinemática & 4 & $7 \%$ \\
\hline Trabalho e Energia & 6 & $10 \%$ \\
\hline Óptica & 6 & $10 \%$ \\
\hline Termologia & 7 & $11 \%$ \\
\hline Ondulatória & 17 & $28 \%$ \\
\hline TOTAIS & 61 & $100 \%$ \\
\hline
\end{tabular}

В таблице 2 показаны предметы из меню физики технического курса химии в IFAP с указанием количества единиц (в двухмесячный период) и года, которые охвачены. Единицы с I по IV необходимо преподавать в течение восьмидесяти (80) учебных часов. В первый год 12 часов обычно используются для обучения модулю I, 28 часов - для обучения модулю II, 20 часов - для модуля III и 20 часов - для модуля IV. На втором году обучения элемент I обычно длится 20 часов, а также каждый из последующих разделов (II, III и IV). На третий год

RC: 78516

Disponível em: https://www.nucleodoconhecimento.com.br/образование-ru/сризика- 
часть I выполняется за 16 часов, часть II - за 36 часов, часть III - за 14 часов, а часть IV - за 14 часов.

Таблица 2. Предметы меню фризики технического курса химии IFAP, по годам и единицам.

\begin{tabular}{|c|c|c|c|c|c|c|}
\hline \multirow[b]{2}{*}{ Unidade } & \multicolumn{6}{|c|}{ Ano } \\
\hline & $1^{\circ}$ Ano & $\begin{array}{c}\mathrm{n}^{\circ} \text { de horas } \\
\text { aulas }\end{array}$ & $2^{\circ}$ Ano & $\begin{array}{c}\mathrm{n}^{\circ} \text { de horas } \\
\text { aulas }\end{array}$ & $3^{\circ}$ Ano & $\begin{array}{c}\mathrm{n}^{\circ} \text { de horas } \\
\text { aulas }\end{array}$ \\
\hline I & \begin{tabular}{|c|} 
Introdução à \\
Fisica e \\
Cinemática \\
\end{tabular} & 12 & $\begin{array}{c}\text { Calore } \\
\text { Temperatura }\end{array}$ & 20 & Eletrostática & 16 \\
\hline II & $\begin{array}{c}\text { Dinâmica } \\
\text { (evidenciando o } \\
\text { conceito de força } \\
\text { e aplicações) } \\
\end{array}$ & 28 & Termodinâmica & 20 & Eletrodinâmica & 36 \\
\hline III & $\begin{array}{c}\begin{array}{c}\text { Trabalho e } \\
\text { Energia }\end{array} \\
\end{array}$ & 20 & $\begin{array}{c}\text { Óptica } \\
\text { Geométrica }\end{array}$ & 20 & Magnetismo & 14 \\
\hline IV & $\begin{array}{c}\text { Gravitação e } \\
\text { Estática dos } \\
\text { Fluidos }\end{array}$ & 20 & $\begin{array}{l}\text { Oscilações e } \\
\text { Ondas }\end{array}$ & 20 & Eletromgnetismo & 14 \\
\hline $\begin{array}{l}\text { no aulas da } \\
\text { matriz anual }\end{array}$ & & 80 & & 80 & & 80 \\
\hline
\end{tabular}

Упрощенная классификация содержания вопросов по фризике ENEM в период с 2014 по 2018 год по количеству и процентному содержанию вопросов представлена в таблице 3. Тематическая тема появляется в $2 \%$ вопросов, за ней следует тема «Электричество + магнестимо» $(7 \%)$, оптика $(10 \%)$, термология (11\%); Волновой (28\%) и Механический (43\%).

Таблица 3. Упрощенная классификация содержания вопросов по фризике ENEM в период с 2014 по 2018 год по количеству и процентному содержанию вопросов.

$\mathrm{RC}: 78516$

Disponível em: https://www.nucleodoconhecimento.com.br/образование-ru/фризика- 


\begin{tabular}{l|c|c|}
\hline Assunto & Quantidade & Porcentagem \\
\hline Tematica & 1 & $2 \%$ \\
\hline Eletricidade + Magnetismo & 4 & $7 \%$ \\
\hline Óptica & 6 & $10 \%$ \\
\hline Termologia & 7 & $11 \%$ \\
\hline Ondulatória & 17 & $28 \%$ \\
\hline Mecânica & 26 & $43 \%$ \\
\hline Total & $\mathbf{6 1}$ & $\mathbf{1 0 0 \%}$ \\
\hline
\end{tabular}

Упрощенная классификация содержания вопросов ENEM по фризике в период с 2014 по 2018 год, разделенная на год, в котором они преподаются на техническом курсе химии в IFAP, показана в таблице 4. Показанный процент относится к доле вопросов ENEM в рамках каждая тема.

Таблица 4. Упрощенная классификация содержания вопросов ENEM по физике в период с 2014 по 2018 год, разделенная на год, в котором они преподаются на техническом курсе химии в IFAP.

\begin{tabular}{|c|c|c|c|c|}
\hline & \multicolumn{4}{|c|}{ Curso técnico em química do IFAP } \\
\hline & $1^{\circ}$ & $\mathbf{2}^{\circ}$ & $\mathbf{3}^{\mathrm{a}}$ & Todos \\
\hline \multirow{3}{*}{$\begin{array}{c}\text { Assuntos com } \\
\text { as porcentagem } \\
\text { de questões }\end{array}$} & \multirow{3}{*}{ Mecânica (43\%) } & Óptica $(10 \%)$ & \multirow{3}{*}{$\begin{array}{c}\text { Eletricidade }+ \\
\text { Magnestismo (7\%) }\end{array}$} & \multirow{3}{*}{ Tematica $(2 \%)$} \\
\hline & & Termologia (11\%) & & \\
\hline & & Ondulatória $(28 \%)$ & & \\
\hline $\begin{array}{c}\text { Porcentagem } \\
\text { Total }\end{array}$ & $43 \%$ & $49 \%$ & $7 \%$ & $100 \%$ \\
\hline
\end{tabular}

На рисунке 1 показано количество вопросов по фризике на ENEM в период с 2014 по 2018 год в зависимости от степени сложности. Количество вопросов, классифрицируемых программой суперпрофрессора как имеющие низкий уровень

RC: 78516

Disponível em: https://www.nucleodoconhecimento.com.br/образование-ru/сризика- 
сложности, уменьшилось с 2014 по 2016 год и снова увеличилось с 2016 по 2018 год. Вопросы средней сложности увеличились с 2014 по 2016 год и уменьшились с 2016 по 2018 год. сложности появятся только в 2015 году.

Рисунок 1 Количество вопросов по фризике на ENEM в период с 2014 по 2018 год в зависимости от степени сложности

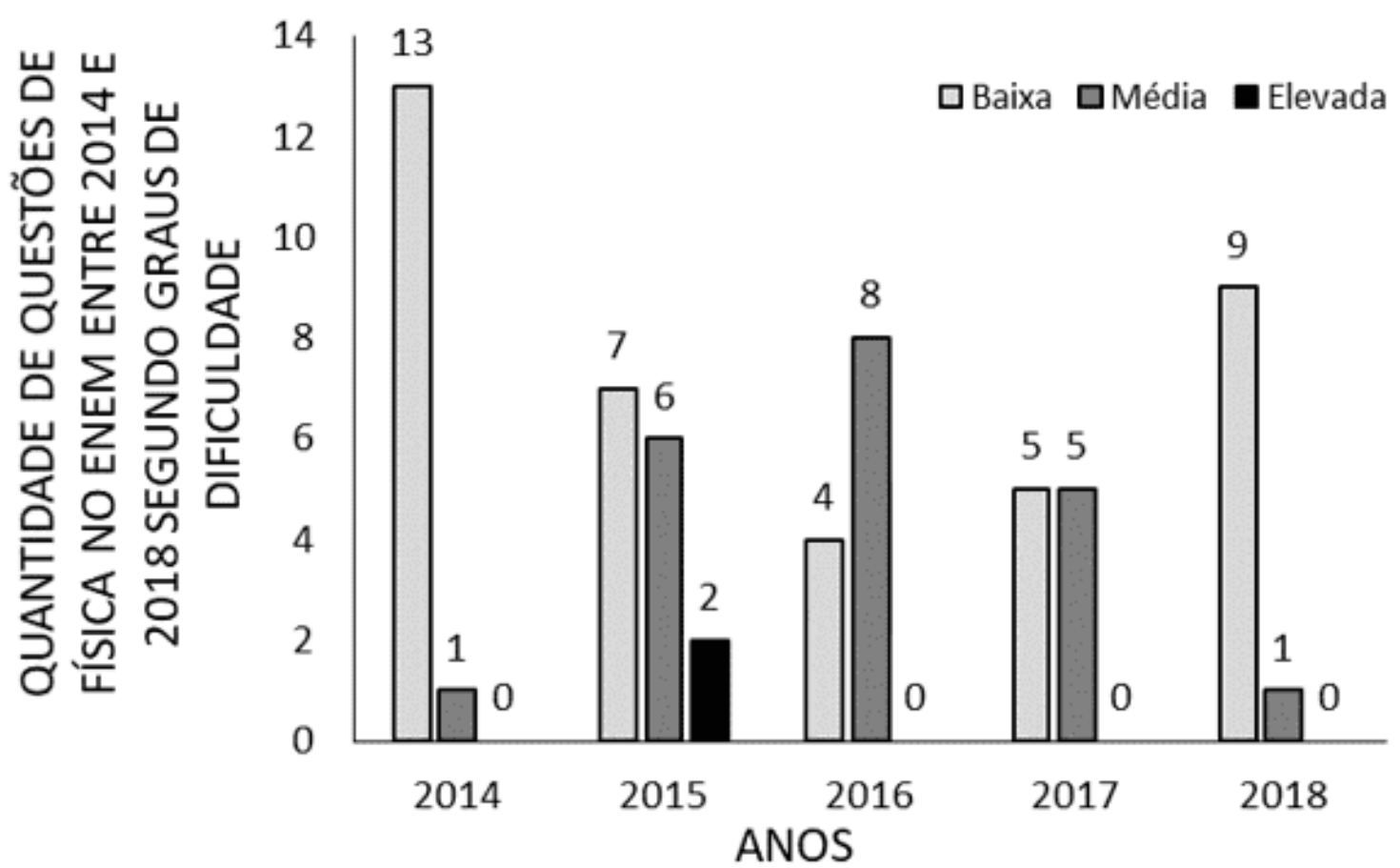

\section{ОБСУЖДЕНИЕ}

Национальный экзамен в средней школе имеет в качестве параметра контекстуализировать вопросы фризического экзамена, связывая их с повседневной жизнью людей (Silveira et al., 2014). В этом смысле разница, представленная между предметами оценки по фризике в изучаемый период (таблица 1), могла возникнуть как следствие такой контекстуализации. В ходе исследования присутствия физики в повседневной жизни работающих студентов были обнаружены вопросы об использовании различных энергий (электрической, химической) в таких ситуациях, как заводы по производству

RC: 78516

Disponível em: https://www.nucleodoconhecimento.com.br/образование-ru/сризика- 
алкоголя и места для установки звукового оборудования в автомобилях (Toti и Pierson, 2010). Оптика также постоянно присутствует в жизни людей. Изучение света может помочь инженеру узнать, сколько тени создаст его спроектированное здание по соседству; или, как чашка или металлический предмет, вы читаете изображение; или даже потому, что небо голубое в солнечный день (Ribeiro и Verdeaux, 2012).

В техническом курсе, как части электромагнетизма, есть введение в специальную теорию относительности, которая является предметом современной фризики (Brasil, 2016). Современная фризика в средней школе еще не является консолидированным содержанием, и нет единого мнения о ее преподавании. Вероятно, по этой причине в ENEM отсутствует эта тема (Silva et al., 2013).

Обычно учебные программы делят учебный год средней школы на четыре двухмесячных. Каждому двухмесячному периоду соответствует блок по 20 часов каждый. В год с 80 часами деление будет справедливым. Однако изучение некоторых предметов занимает больше времени, чем других (таблица 2). Разница между плановым временем и реальным временем для каждой единицы, вероятно, связана с фррагментированным программированием контента. Таким образом, обучение становится свободным, а представленное, фрагментированное содержание имеет различные фракторы сложности, требующие меньше или больше часов для его завершения (Gaspar, 1997). Кроме того, классное время в традиционном классе также тратится на другие задачи (звонок, заметки), а не на преподавание самой дисциплины (Pires и Veit, 2006).

В справочной матрице Enem большинство объектов исследования относятся к механике. В этой же матрице у субъектов волны, оптики, электромагнетизма и термодинамики одинаковое количество объектов. Но наличие этих предметов в вопросах не похоже. Только механика присутствует как в этой матрице, так и в

$\mathrm{RC}: 78516$

Disponível em: https://www.nucleodoconhecimento.com.br/образование-ru/фризика- 
вопросах (таблица 3). Справочная матрица включает в себя в теме «Механика» множество различных концепций, чего нет в других предметах, например, в волнах. Возможно, это разделение, практикуемое ENEM и отличающееся от разделения технических высших учебных заведений, является причиной наблюдаемой процентной разницы (Brasil, 2015).

Некоторый контент, изучаемый в фризическом компоненте в рамках технического курса химии В IFAP, имеет, например, заряд 80 часов (электричество + магнетизм) и соответствует 7\% контента, заряженного в ENEM. Другие, такие как термология, преподаются в техническом образовании за 40 часов и соответствуют 11\% национального экзамена. Третьи, как волна, составляют 28\% оценки ENEM и преподаются за 20 часов. Это несоответствие, вероятно, происходит из-за того, что фундаментальная роль IFAP в вышеупомянутом курсе заключается в обучении технических специалистов по химии (brasil, 2019). Это не означает, что студенты, получившие среднее техническое образование, не сдают ENEM для поступления в высшие учебные заведения.

Преподавание фризики по-прежнему сопряжено с трудностями в плане усвоения знаний студентами, а это означает, что большинство студентов не демонстрируют удовлетворительных результатов по этой дисциплине (Sbf, 2011; Barroso et al., 2018).

Тест ENEM должен соответствовать тому, что ученик изучил в старшей школе (обычной или технической). Можно было увидеть, что сложность ENEM изменилась с годами (рисунок 1). Попытка повысить сложность вопросов национального экзамена (с 2014 по 2016 год) в последующие два года была отменена. Вероятно, поскольку преподавание физики на среднем уровне все еще имеет низкую эффективность усвоения знаний, возможно, это повлияло на решение снизить уровень сложности этого компонента на экзаменах 2017 и 2018 годов (Barroso et al., 2018).

$\mathrm{RC}: 78516$

Disponível em: https://www.nucleodoconhecimento.com.br/образование-ru/сризика- 


\section{ВЫВОД}

В преподавании фризики на техническом курсе химии в IFAP нет раздела, который отдавал бы приоритет предметам, наиболее широко представленным в ENEM.

ENEM обычно контекстуализирует свои вопросы. Это может быть обычной практикой в фризике средней школы, так как это поможет вам лучше понять. Кроме того, необходимо не фррагментировать содержание во время обучения или по мере его совмещения с другими предметами.

Технический курс IFAP не будет подходящим местом обучения для тех, кто просто хочет закончить среднюю школу. Содержание выходит за рамки того, что требуется, но с вырезами, ориентированными на техническую часть, включая лабораторные практики и строго технические дисциплины.

Отсутствие междисциплинарности и контекстуализации затрудняет усвоение содержания, фоормируя у учащихся трудности с мышлением о фризике.

\section{РЕКОМЕНДАЦИИ}

BARROSO, M. F.; RUBINI, G.; SILVA, T. Dificuldades na aprendizagem de Física sob a ótica dos resultados do Enem. Rev. Bras. Ensino Fís., v. 40, n. 4, p. e4402, 2018.

BRASIL. Matriz de Referência Enem. Brasilia DF, 2015. Disponível em: < http://download.inep.gov.br/download/enem/matriz_referencia.pdf >. Acesso em: 25 mar 2020.

Curso Técnico de Nível Médio em Química na Forma Integrada Regime Integral: Plano de Curso. Macapá AP, 2016. Disponível em: < $\mathrm{RC}: 78516$

Disponível em: https://www.nucleodoconhecimento.com.br/образование-ru/фризика- 
https://portal.ifap.edu.br/index.php/publicacoes/item/1100-resolucao-n-20-2018consup >. Acesso em: 27 abril 2019.

. Expansão da Rede Federal. Rede Federal de Educação Profissional, Científica e Tecnológica. 2018. Disponível em: < http://redefederal.mec.gov.br/expansao-da-rede-federal >. Acesso em: 27 abril 2019. . Curso Técnico em Química - Integrado - Campus Macapá. Macapá AP, 2019 Disponível em:

http://www.ifap.edu.br/index.php/component/content/article?id=398 >. Acesso em: 27 abril 2019.

CASTRO, G. N. V. et al. Análise de Eficiência Acadêmica dos cursos subsequentes, nas modalidades à distância e presencial, ofertados pelo Instituto Federal do Amapá (2018). Research, Society and Development, v. 9, n. 8, p. e208985262, 2020. https://rsdjournal.org/index.php/rsd/article/view/5262

GASPAR, A. Cinqüenta anos de ensino de Física: Muitos equívocos, alguns acertos e a necessidade do resgate do papel do professor $\underline{X V \text { Encontro de }}$ Físicos do norte e Nordeste Natal RN 1997.

MARQUES, J. D. C. et al. Nível Médio Técnico e Cursos de Graduação: comparativo de vagas e ingressantes no Instituto Federal do Amapá, Brasil (20172018). Research, Society and Development, v. 9, n. 8, p. e228985375, 2020 https://rsdjournal.org/index.php/rsd/article/view/5375

PACHECO, E. M. Os Institutos Federais: Uma Revolução na Educação Profissional e Tecnológica. Natal RN: IFRN, 2010. 28p.

PENHA, A. C. F. M. et al. Matrículas da Educação Especial na Educação Profissional Técnica de Nível Médio no Estado do Amapá (2015-2018). Research,

$\mathrm{RC}: 78516$

Disponível em: https://www.nucleodoconhecimento.com.br/образование-ru/сризика- 
Society and Development, v. 9, n. 7, p. e881974867, 2020. https://rsdjournal.org/index.php/rsd/article/view/4867

PIRES, M. A.; VEIT, E. A. Tecnologias de Informação e Comunicação para ampliar e motivar o aprendizado de Fısica no Ensino Medio. Revista Brasileira de Ensino de Fısica, v. 28, n. 2, p. $241-248,2006$.

RIBEIRO, J. L. P.; VERDEAUX, M. D. F. D. S. Atividades experimentais no ensino de óptica: uma revisão. Revista Brasileira de Ensino de Fısica, v. 34, n. 4, p. 110,2012

SBF. Carta aberta ao Inep quanto à adoção do Exame Nacional do Ensino Médio como critério de ingresso nas Universidades. São Paulo SP, 2011. Disponível em: $<\quad$ http://www.sbfisica.org.br/v1/arquivos_diversos/noticias/maio2014/carta-aoINEP.pdf >. Acesso em: 05 fev 2021.

SILVA, J. R. N. D.; ARENGHI, L. E. B.; LINO, A. Porque inserir física moderna e contemporânea no ensino médio? Uma revisão das justificativas dos trabalhos acadêmicos. R. B. E. C. T., v. 6, n. 1, p. 1-15, 2013.

SILVEIRA, F. L.; BARBOSA, M. C. B.; SILVA, R. Exame Nacional do Ensino Médio (ENEM): Uma análise crítica Rev. Bras. Ensino Fís., v. 37, n. 1, p. 1101, 2015.

SILVEIRA, F. L.; STILCK, J.; BARBOSA, M. Comunicações: Manifesto sobre a qualidade das questões de Física na Prova de Ciências da natureza no Exame Nacional de Ensino Médio. Caderno Brasileiro de Ensino de Física, v. 31, n. 2, p. 473-479, 2014.

TOTI, F. A.; PIERSON, A. H. C. Elementos para uma aproximação entre a física no ensino médio e o cotidiano de trabalho de estudantes trabalhadores. Investigações em Ensino de Ciência, v. 15, n. 3, p. 527-552, 2010

$\mathrm{RC}: 78516$

Disponível em: https://www.nucleodoconhecimento.com.br/образование-ru/фризика- 
Размещено: март 2021 г.

Утверждено: март 2021 г.

RC: 78516

Disponível em: https://www.nucleodoconhecimento.com.br/образование-ru/сризикаB-enem 